\title{
Impact of podcasting on English learners' motivation in asynchronous e-learning environment
}

\author{
Oksana Marunevich", Olga Bessarabova, Elmira Shefieva, and Victoria Razhina \\ Rostov State Transport University, Rostov-on-Don, Russia
}

\begin{abstract}
We strongly believe that within the next few years, podcasting is destined to become an important component in the learning environment of the university since educators are trying to integrate the best use of advanced technologies in their courses and remain vigilant to the everchanging technological landscape. The study aims to validate the idea that podcasts offer teachers a platform to supplement their materials. Despite the potential benefits of podcasts for university education, few researchers have addressed the problem of the influence of podcasting on English learners' motivation. Based on a survey with 211 students of Rostov State Transport University, this paper focuses on motivational factors for using podcasts when taking an English language course. We found two dimensions of motivating factors (entertainment and convenience) to be prominent for active podcasts use.
\end{abstract}

\section{Introduction.}

In the recent decade, the application of podcasts witnessed rapid growth in a wide array of fields, including entertainment, journalism, scientific research, and education. The word "podcast" was created by combining "iPod" and "broadcast". Merriam-Webster Dictionary defines it as "a program, as of music or talk, made available in a digital format for automatic download over the internet" [1]. As reported by Notess [2], a podcast is a medium that comprises audio or video files to which individuals freely subscribe via the Internet. Kidd \& Chen [3] interpret podcasts as multimedia files distributed via networks using rapid simple syndication feeds, to be played or downloaded on electronic devices. Rossell-Aguilar [4] points out that podcast content incorporates image, video, and audio materials. Podcast length and frequency can be different, from hourly 5-min newscasts, through daily 20 -min storytelling to weekly 60 -min co-hosted interviews. The scope of the given paper is, however, limited to audio podcasts (hereby simply referred to as podcasts) since they are the most commonly employed issues in the learning environment of the university.

The ease of use is what makes podcasts so revolutionary and omnipresent learning tool. Indeed, the only action a person has to take is to subscribe to download the podcast content automatically. The initial subscription allows users not to worry about whether or not they

\footnotetext{
* Corresponding author: oks.marunevich@mail.ru
} 
are obtaining the most updated information or the latest rendition of a podcast. The aforementioned simplicity leads to the true power of podcasting, which is considered to be a series of time-shifted talk shows to be heard whenever and wherever it is most convenient for the user [5].

A variety of mobile phones in the market makes podcasts extremely available as well as desirable in education. Today's mobile phones are actively used in a range of innovative ways. Simonova \& Marunevich [6] describe the usefulness of mobile technology in terms of contemporary public agenda which has significantly altered the way people live, think, get an education, and perceive things around. Affordable, lightweight, and versatile fourth (4G) and fifth-generation (5G) models provide learners with multiple means of communication (by voice, messages, e-mail, or videoconferences) and access to information and entertainment. In 2010, Olli-Pekka Kallasvuo, a CEO and President of Nokia, stated that "a mobile phone is a gateway, and oftentimes the only means to knowledge, entertainment and communications for people [...]. They have become vital to the lives and businesses of the people that use them" [7].

Zinger et al. [8] draw our attention that being aware of how learners are adapting to the advanced technologies and if they remain a relevant form of instruction appears crucial to a successful pedagogy. Riddell et al. [9] specify that when adopting new technologies, educators must also understand how and why they are being embraced by learners to employ them more effectively. After comparing podcasting with other educational technologies and traditional teaching methods, McGarr [10] concludes that its ultimate use is determined by the huge potential of the technology.

When podcasting was first brought into education, neither teachers nor students knew how to exploit them. Teachers preferred dictating lectures in the classroom only, while learners were used to taking notes or reading textbooks. Students slowly become habituated to podcasting as additional learning materials that allowed them to, "manage the rest of the course materials in a more efficient manner" [11]. Besides, podcasting much assisted in decreasing the feeling of information overload. In their investigation, Fernandez et al. [11], show that students usually take online learning due to family, job, or time restraints and comment on abundant accessibility of podcasts since because of the lack of a permanent place to study students appreciate materials that can be used in different spots, including cafes, public transport, etc. Even in the pre-COVID era, online learners were constantly on the move and their major focus in life was not their education. That's why university and college teachers growingly adopted podcasts for lectures, which had a positive impact on students' performance on exams [12]. Educators all over the world have become interested in using podcasts and tend to develop podcast feeds with additional lectures that students can download when they miss a class, need to catch up in a course or prepare for exams. For instance, iTunes $U$ includes more than a thousand History, Engineering, Business, Literature, Art \& Architecture, Health \& Medicine courses from Harvard, Stanford, Massachusetts Institute of Technology, La Sorbonne, Oxford, and other recognized universities as of March 2021.

According to the Pew Research Center Report (2020), the current university-aged generation, called Generation Z (individuals born between 1995 and 2010), is the most media and technology-friendly generation [13]. Besides, they consider higher education to be more important than Millennials (individuals between 1980 and 1994). For instance, the Annie E. Casey Foundation's KIDS COUNT Data Center covers the following trend: from 2000 to 2020, the share of 16- to 19-year olds who were not high school students or graduates came down from $11 \%$ to $4 \%$, while the share of 18 - to 24 -year-olds who were university/college students or graduates, on the contrary, increased from $36 \%$ to $49 \%$ [14].

Given the rapid growth of using podcasts in an educational setting for Generation Zers, especially during the COVID and post-COVID era, it is essential to address the question of 
the influence of podcasting on students' motivation in the asynchronous learning environment in the context of new educational challenges and conditions. Fostering podcast use is promising for higher education; however, we strongly believe that study is needed to help educators understand the possible impact of new technologies on university students' motivation. Hence, this paper is aimed at scrutinizing what leads students to use podcasts.

\section{Methodology}

The initial sample was composed of 211 students of Electromechanical, Transportation Management and Management Information Technologies Departments of Rostov State Transport University. The rapid development of technology, transport, and communications, impose the urgent need for highly skilled professionals who speak at least one foreign language to participate in international projects to drive social impact and solve global challenges [15].

The average age of the participants was 18 years old. Males and females comprised $86.2 \%(n=182)$ and $13.8 \%(n=29)$ of the cohort, respectively. Regarding students' year at university, freshmen comprised slightly under three-fourths $(73.5 \%)$ of the sample followed by sophomores $(26.5 \%)$. All participants could be described as having approximately equal language proficiency.

The study was carried out for an academic year starting on September 2, 2019, and finishing on May 31, 2020.

We used podcasts to teach English in an asynchronous e-learning environment since podcasts provide students with a perfect opportunity to get personal involvement in mastering diverse skills of the English language.

The main podcast selected for this study was EnglishClass101 (available on www.englisclass 101.com and iTunes). Students can choose any podcast from four levels of learning: starter, beginner, intermediate, and advanced. The podcasts are put before the public by hosts, who act dialogues or monologues in different scenes. After a certain scene has been performed, it's repeated at a much slower speed. Besides, each podcast contains culturally or historically relevant information, as well as a focus on vocabulary and grammar.

We modified the method of analyzing motivation factors suggested by Pappacharissi and Rubin [16] that include: (1) relaxation, (2) companionship, (3) habit, (4) pastime, (5) entertainment, (6) social interaction, (7) information, (8) arousal, (9) escape, (10) convenience, and (11) voyeurism. Previous studies reported on the acceptable reliability $(\alpha$ $>0.70$ ) of the given method. To examine the use of podcasting on students' motivation, we replaced the voyeurism factor with the education one.

Furthermore, we proposed students evaluate their eagerness to listen to podcasts by commenting on the following statements: (1) I would utilize podcasts because they help study English; (2) I would use podcasts because I can listen to them when I miss class; (3) I would use podcasts while preparing for English language test or exam.

Hence, the aforementioned motivation factors include three statements each. We asked the participants to respond to all of them employing a 5-point, Likert-type scale which ranged from 1 (strongly disagree) through 2 (disagree), 3 (neutral), and 4 (agree) to 5 (strongly agree). Finally, we asked participants to estimate the average weekly hours of listening to podcasts. 


\section{Results \& Discussion}

Our findings demonstrate that before the experiment the majority of students (63\%) used podcasts less than one hour per week (Fig. 1). From graph 1, we can note that after the experiment they started using podcasts more. Students admitted that podcasts actually motivated them in learning English, increased their listening skills, and enlarged vocabulary.

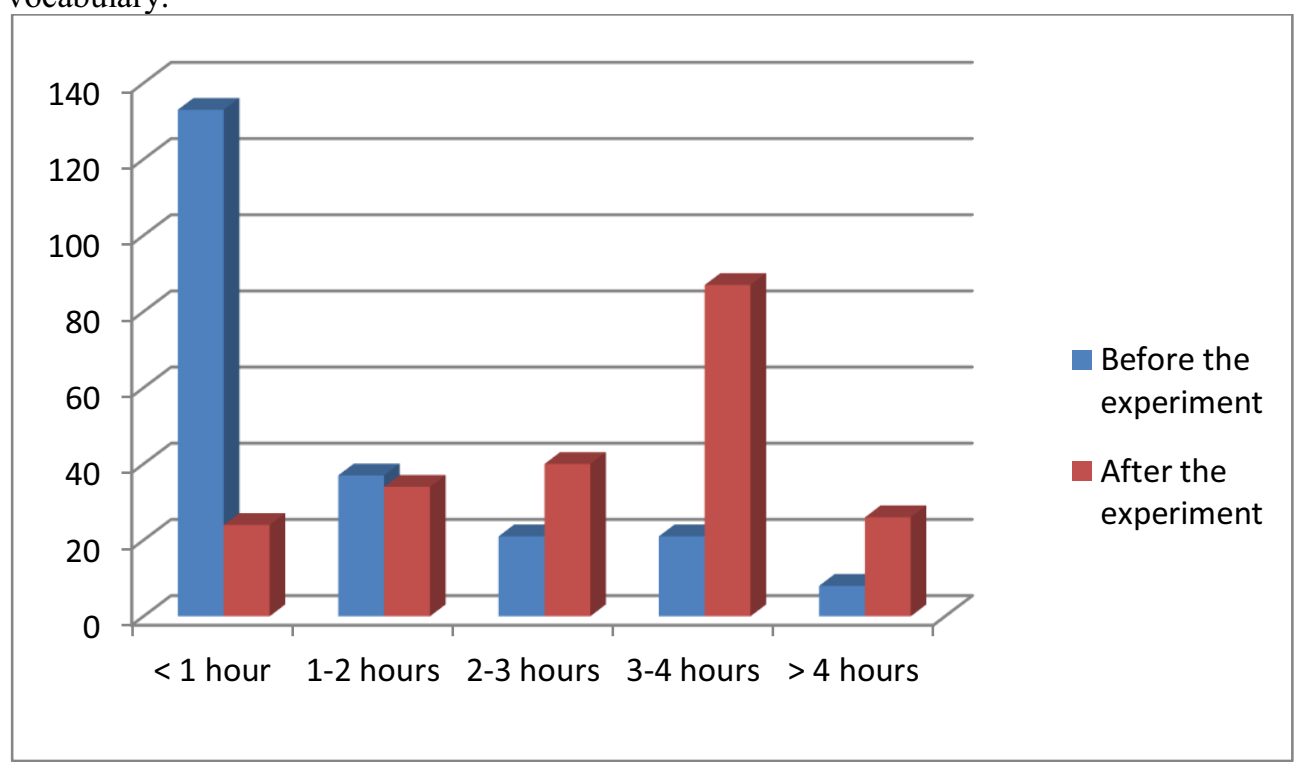

Fig. 1. Weekly frequency of podcasting before and after the experiment

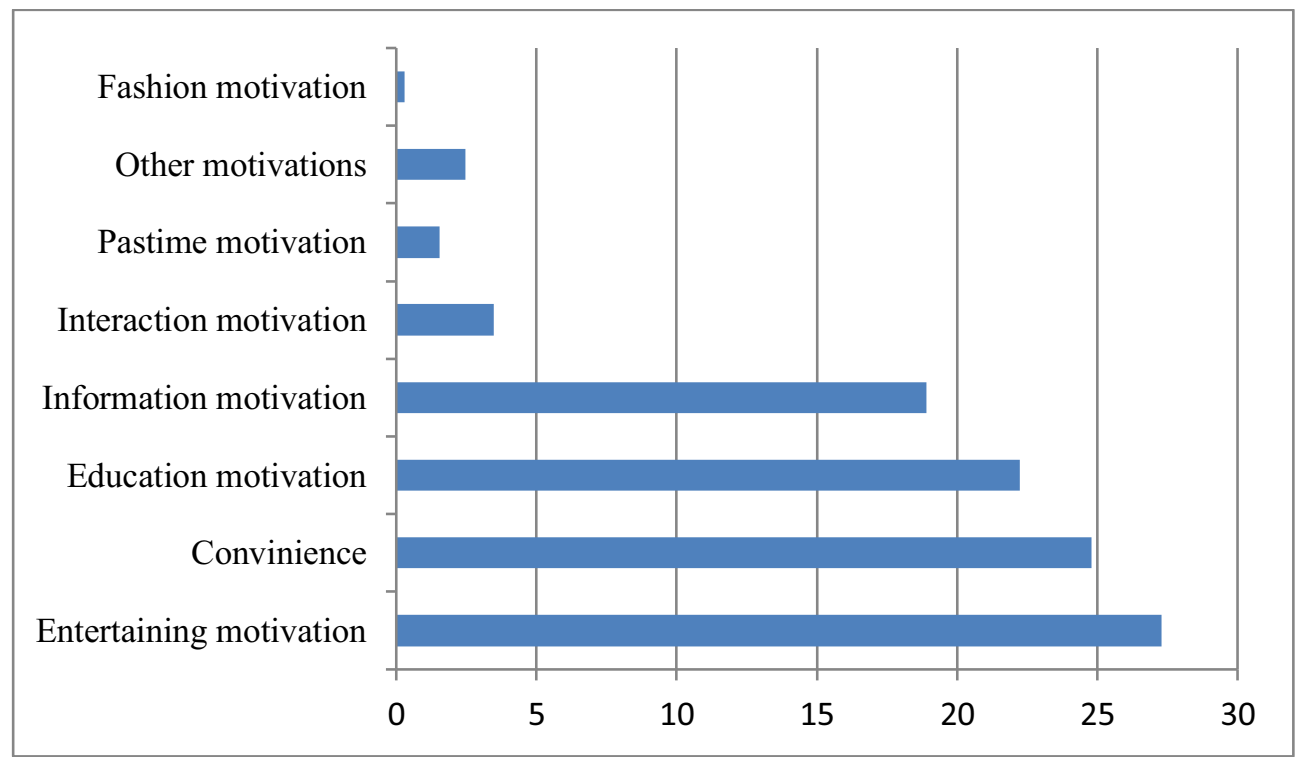

Fig. 2. Motivations for learning English

When analyzing the motivations for podcasting, entertainment and convenience appeared to be the most important factors (Fig. 2). Students described their motivations for learning English by using podcasts in a variety of ways. 211 subjects gave 318 answers to the open- 
ended question, "How do podcasts motivate you to study English?" $27.28 \%(n=88)$ of the total answers, reported on entertaining motivation since the podcasts are both funny and educational. Approximately a quarter $(24.8 \%, \mathrm{n}=80)$ were incorporated into convenience motivation as students could improve their English during any activity that did not require full attention. $22.32 \%(\mathrm{n}=72)$ fitted into the education motivation. Combining storytelling with insights on student life and real-world issues, EnglishClass101 podcasts encouraged students to learn new vocabulary, idioms, collocations, etc., and to use them in their everyday speech. $18.91 \%(n=61)$ mentioned information motivation. Indeed, the podcasts that we have chosen for the experiment are exceptionally informative and help students to broaden their horizons. Social interaction motivation $(2.48 \%, \mathrm{n}=8)$ was followed by pastime one $(1.55 \%, \mathrm{n}=5)$. Students let us know that podcasts much assisted in their communication with friends from English-speaking countries as podcasts contained a variety of examples of lively conversation between close friends and numerous patterns for effective communication. Finally, $2.48 \%(n=8)$ of the total answers were designated to other motivations. Besides, we identified one answer $(0.31 \%)$, which did not suit any of the motivations. The first-year student confessed that he listened to podcasts because it is a contemporary trend and he just strived for keeping up with the time.

In general, out of all motivations, the education one appeared to be the key motivating factor that definitely reflects a major function of employing podcasts for learning English at university.

\section{Conclusion}

The evidence from this study implies that podcasting is an effective language teaching tool, which provides both teachers and students with the advantage of improving English language skills beyond the classroom and accessing course materials at any time and in any location.

This study shed light on the impact of podcasting on English learners' motivation. The findings of the study indicate that students did not use podcasts before the experiment. However, later, they started to listen to podcasts for educational and informational purposes. Besides, an obvious benefit of podcasts is their convenience, relaxation, and social aspects.

\section{References}

1 Merriam-Webster Dictionary, Definition of Podcast (2021), Retrieved from https://www.merriam-webster.com/dictionary/podcast

2 G.R. Notess, Casting the Net: Podcasting and Screencasting, Online, 29(6), pp. 43-45 (2005).

3 T.T. Kidd, \& I.L. Chen (Eds.), Wired for learning: An educator's guide to web 2.0. Charlotte, Information Age Publishing (2009).

4 F Rosell-Aguilar, Top of the pods - In search of a podcasting "podagogy" for language learning, Computer Assisted Language Learning, 20(5), pp. 471-492 (2007).

5 R. H. Savel, E. B.Goldstein, E. N. Perencevich, \& P. B. Angood, The iCritical Care Podcast: A Novel Medium for Critical Care Communication and Education, Journal of the American Medical Informatics Association, 14(1), pp. 94-99 (2007). https://doi.org/10.1197/jamia.M2205

6 Simonova O.B., Marunevich O.V. The theoretical generalization of the scientific background of the QR codes methods in teaching English in the high school, Problems of Modern Pedagogical Education, 70 (3), pp.160-161 (2021). 
7 Dialing for development: How mobile phones are transforming the lives of millions, Retrieved from https://www.wipo.int/wipo_magazine/en/2010/05/article_0002.html

8 D. Zinger, T. Tate, M. Warschauer, Learning and Teaching with Technology: Technological Pedagogy and Teacher Practice, In The SAGE Handbook of Research on Teacher Education, SAGE, pp.577-593 (2017).

9 J. Riddell, A. Swaminathan, M. Lee, M. Abdiwahab, R. Rogers, \& S. Rezaie, A Survey of Emergency Medicine Residents' Use of Educational Podcasts, Western Journal of Emergency Medicine, 18(2), pp, 217-220 (2017). https://doi.org/10.5811/westjem.2011.5.6700

$10 \mathrm{O}$. McGarr, A review of podcasting in higher education: Its influence on the traditional lecture, Australasian Journal of Educational Technology, 25(3), pp. 309-321 (2009). https://doi.org/10.14742/ajet.1136

11 V. Fernandez, P. Simo, \& J. M. Sallan, Podcasting: A new technological tool to facilitate good practice in higher education, Computers and Education, 53(2), pp. 385392 (2009). https://doi.org/10.1016/j.compedu.2009.02.014

12 D. McKinney, J.L. Dyck, \& E.S. Luber, iTunes University and the classroom: Can podcasts replace Professors? Computers and Education, 52(3), pp. 617-623 (2019). https://doi.org/10.1016/j.compedu.2008.11.004

13 In the Cusp of Adulthood and Facing an Uncertain Future: What We Know about Gen Z So Far, Retrieved from https://www.pewresearch.org/social-trends/2020/05/14/on-thecusp-of-adulthood-and-facing-an-uncertain-future-what-we-know-about-gen-z-so-far-2/

14 Annie E. Casey Foundation: Statistics Snapshot: Generation Z and Education (2020), Retrieved from https://www.aecf.org/blog/generation-Z-and-education.

15 M.E. Shevchuck, O.V. Marunevich, Concept Railway as a unit of knowledge formation in the process of studying foreign language at transport university, Proceedings of the All-Russian scientific-practical conference with international participation Rational Environmental Management as the Basis of Sustainable Development, Chechen State Pedagogical University, pp. 540-544 (2020).

16 Z. Pappacharissi, A.M. Rubin, Predictors of Internet Use, Journal of Broadcasting \& Electronic Media, 44, pp. 175-196 (2000). doi: doi:10.1207/s15506878jobem4402_2. 